\title{
Canada lags on transparency of industry-doctor relationships
}

$\mathrm{T}$ he United States will soon be taking a big step toward improving the transparency of financial ties between the medical industry and physicians by requiring all drug and medical device makers to disclose gifts and payments to doctors. Will Canada follow suit?

"I have not heard a hint of anything like this happening in Canada," says Sergio Sismondo, editor of Social Studies of Science and a philosophy professor at Queen's University in Kingston, Ontario.

"We don't have anything like this kind of transparency," adds Sismondo, who has written extensively on the influence the pharmaceutical industry has on medical research and literature. "The United States is leading the pack."

As part of the Affordable Care Act in the US, the Centers for Medicare \& Medicaid Services, the government agency that administers public insurance programs, will begin posting industry payments to physicians on a publicly accessible website by Sept. 20, 2014. Data collection was supposed to have started in 2012 but was pushed back because of delays in finalizing the regulations.

Though Canada may not have a similar law in the works, Canadian drug companies are well aware of the push to shed more light on their dealings with doctors, according to $\mathrm{Rx} \& \mathrm{D}$, the national association that represents the country's research-based pharmaceutical industry.

"We are aware that a number of other jurisdictions have taken steps to formalize processes for disclosure of such payments," Rx\&D President Russell Williams writes in an email. "Our Code of Ethical Practices currently addresses transparency in relation to how our members support health charities and patient advocacy groups. Rx\&D is currently discussing different approaches regarding disclosure of payments to physicians."

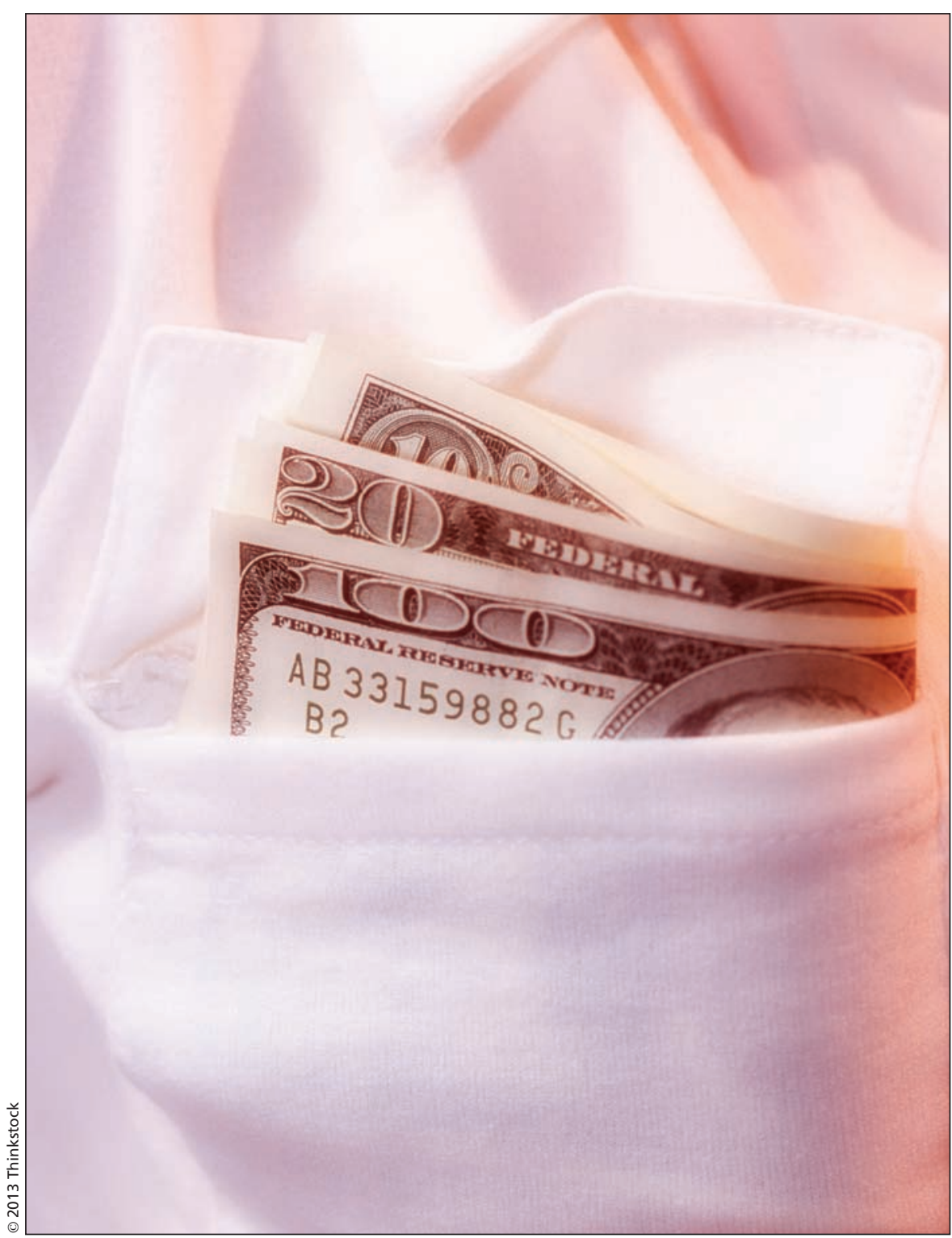

US drug and medical device makers who do not comply with the new law could be fined US\$10 000 or up to \$US100 000 if they knowingly withhold payment information.

The new law in the US holds great potential in two areas in particular, suggests Dr. Robert Steinbrook, professor (adjunct) of internal medicine at the Yale School of Medicine in New Haven, Connecticut. Actual dollar amounts will be disclosed as opposed to merely identifying a physician as a consultant or speaker. Second, it will provide an opportunity to check actual payments against those that physicians have voluntarily disclosed in the past.

"The big picture is that this information is going to be in the public domain, and industry payments to physicians and teaching hospitals will be known. The information should be accurate, and that will be an important step forward," 
says Steinbrook. "Will there be gaming of the system? Will the website be as clear as people hope it will be? That's hard to know."

Steinbrook and a colleague have suggested that "transparency reports" could "shed a bright light on the extensive financial relationships between industry and physicians and teaching hospitals" (JAMA 2012;307:1029-30). But it is important, they noted, that the Centers for Medicare \& Medicaid Services create a state-of-the-art website and resist pressure to weaken the regulations. "The medical profession and the public deserve no less," they wrote.

Still, getting this project up and running smoothly will be anything but trivial, says Steinbrook. It will take a lot of work and large sums of money to collect and verify all the information. And there is no way of knowing if the website will be useful or a dud until it goes live.

"We haven't actually seen anything yet," says Steinbrook. "When we actually see it - when we can look up a particular physician or payments from a particular company - that is going to be the test of how useful this is."

The potential is quite high, though, for the website to unveil some astonishing figures, according to Sismondo. Records opened to the public during US court proceedings have shown that payments to doctors for services such as speaking engagements can be huge, sometimes in excess of US $\$ 100000$ a year.

"It's a good thing," says Sismondo, referring to the forthcoming website. "My guess is that what it's going to reveal is going to be spectacular in terms of the connections between industry and physicians."

Drug and medical device makers are also likely to comply with the new law, suggests Sismondo, considering the penalties for failing to do so. A company will be fined US\$10 000 for failing to report a gift. If a company is found to knowingly omit payment information, it can be dinged up to US\$100 000 .

"They are probably going to follow the letter of the law on this one," says Sismondo. "They may be looking for ways of minimizing the amounts that show up on these charts, but I suspect they will be following the law."

How many US physicians will be affected by the new regulations is impossible to know, but is estimated to be in the hundreds of thousands.

According to a news article published by the American Medical Asso- ciation, estimates indicate that "less than half of physicians, or about 449,000 , have financial relationships with pharmaceutical or device manufacturers that will need to be reported publicly" (www.ama-assn.org/amednews /2013/02/11/gvl10211.htm).

Though he wonders where that estimate came from, Sismondo suggests that if it is even close to accurate, it "really is an indication of the substantial influence that these companies are having over the practice of medicine in the United States."

Figures on payments to doctors in Canada are also hard to come by, so there is no way of knowing for certain if the connection between industry and medicine is as common north of the border.

"As a good Canadian, always thinking the best of my doctors, I want to say that, surely, we cannot have that kind of a connection," says Sismondo. "The level of industry influence on doctors in the United States is extraordinary. It's very, very hard for me to believe it could be the same in Canada. But we have so little data that we actually don't know." - Roger Collier, CMAJ

CMAJ 2013. DOI:10.1503/cmaj.109-4418 